\title{
THE AGREEMENTS CONCLUDED WITHIN THE PROCEDURE OF MEDIATION: QUESTIONS OF EFFICIENCY
}

\author{
Irina A. Stepanova \\ Notary of Volgograd, Volgograd, Russian Federation
}

\begin{abstract}
Introduction: now the high level of conflictness in the enterprise environment is observed that in turn affects load of the judicial system. The legislator, being in search of optimum ways of settlement of the arising conflicts and ways of decrease in load of the judicial system, adopted the Federal law of 27.07.2010 No. 193-FZ "About the alternative procedure of settlement of disputes with participation of the intermediary (the procedure of mediation)" which regulates an order of holding a procedure of mediation by the parties and also allocates a number of agreements to which number carries the agreement on application of the procedure of mediation, the agreement on holding a procedure of mediation, the mediativny agreement. Advantages of the conclusion of the designated agreements are caused by advantages of the corresponding alternative method of settlement of the conflicts. Result of settlement of the conflict by means of mediation without case referral for consideration to court is not declaration of the winner and defeated, and the conclusion of the mediativny agreement reflecting interests and satisfying requirements of all parties of the conflict. Proceeding from it, it is supposed that the mediativny agreement will be executed in a voluntary order. At the same time, the absence in the legislation of the mechanism of compulsory performance of mediativny agreements does not promote public awareness of this alternative method of settlement of the civil conflicts. Besides, the wording of Paragraph 1 of Article 4 of the Federal law of 27.07.2010 No. 193-FZ "About the alternative procedure of settlement of disputes with participation of the intermediary (the procedure of mediation)" actually leads to a situation of ignoring by court of the agreement on application of the procedure of mediation concluded by the parties that is inadmissible. In this regard definition of degree of efficiency of mediativny agreements and agreements on application of the procedure of mediation and also the problems of legal regulation which are negatively affecting promoting of practice of their conclusion acts as a main objective of the real research. Methods: the methodological basis of the study was a combination of general scientific (dialectic, inductive, deductive) and private scientific (formal legal, interpretative) methods. Results: in work an assessment of efficiency of separate types of the agreements connected with the procedure of mediation, and signed before case referral for considerations in court is given, the problems of their legal regulation connected, in particular, with existence of the negative judicial practice ignoring the fact of non-execution of the concluded agreement on application of the procedure of mediation and also lack of the compulsory mechanism of performance of mediativny agreements are revealed. Conclusions: following the results of the conducted research the author formulated the offers directed to an exception of the revealed problems of legal regulation of mediativny agreements and agreements on application of the procedure of mediation by means of introduction of amendments to the current legislation. Besides, the author pays attention to need of development of practical recommendations about the conclusion of mediativny agreements for increase in their voluntary execution.
\end{abstract}

Key words: mediation, mediation agreement, contract, dispute, conflict, feasibility.

Citation. Stepanova I.A. The Agreements Concluded within the Procedure of Mediation: Questions of Efficiency. Legal Concept, 2018, vol. 17, no. 4, pp. 117-124. DOI: https://doi.org/10.15688/lc.jvolsu.2018.4.17

\section{СОГЛАШЕНИЯ, ЗАКЛЮЧАЕМЫЕ В РАМКАХ ПРОЦЕДУРЫ МЕДИАЦИИ: ВОПРОСЫ ЭФФЕКТИВНОСТИ}

\section{Ирина Александровна Степанова}

Нотариус города Волгограда, г. Волгоград, Российская Федерация 
Введение: в настоящее время наблюдается высокий уровень конфликтности в предпринимательской среде, что, в свою очередь, отражается на загруженности судебной системы.

Законодатель, находясь в поиске оптимальных путей урегулирования возникающих конфликтов и способов снижения загруженности судебной системы, принял Федеральный закон от 27.07.2010 № 193-Ф3 «Об альтернативной процедуре урегулирования споров с участием посредника (процедуре медиации)», который регламентирует порядок проведения сторонами процедуры медиации, а также выделяет ряд соглашений, к числу которых относит соглашение о применении процедуры медиации, соглашение о проведении процедуры медиации, медиативное соглашение.

Преимущества заключения обозначенных соглашений обусловлены преимуществами соответствующего альтернативного метода урегулирования конфликтов.

Итогом урегулирования конфликта посредством медиации без передачи дела на рассмотрение в суд является не провозглашение победителя и побежденного, а заключение медиативного соглашения, отражающего интересы и удовлетворяющего потребности всех сторон конфликта. Исходя из этого предполагается, что медиативное соглашение будет исполнено в добровольном порядке.

Вместе с тем отсутствие в законодательстве механизма принудительного исполнения медиативных соглашений не способствует популяризации данного альтернативного метода урегулирования гражданскоправовых конфликтов.

Кроме того, формулировка п. 1 ст. 4 Федерального закона от 27.07.2010 № 193-Ф3 «Об альтернативной процедуре урегулирования споров с участием посредника (процедуре медиации)» фактически приводит к ситуации игнорирования судом заключенного сторонами соглашения о применении процедуры медиации, что недопустимо.

В связи с этим основной целью настоящего исследования выступает определение степени эффективности медиативных соглашений и соглашений о применении процедуры медиации, а также проблем правового регулирования, отрицательно отражающихся на популяризации практики их заключения.

Методы: методологическую основу исследования составила совокупность общенаучных (диалектический, индуктивный, дедуктивный) и частнонаучных (формально-юридический, интерпретационный) методов. Результаты: в работе дана оценка эффективности отдельных видов соглашений, связанных с процедурой медиации и заключаемых до передачи дела на рассмотрение в суд, выявлены проблемы их правового регулирования, связанные, в частности, с существованием негативной судебной практики, игнорирующей факт неисполнения заключенного соглашения о применении процедуры медиации, а также отсутствием принудительного механизма исполнения медиативных соглашений. Выводы: по итогам проведенного исследования автором сформулированы предложения, направленные на исключение выявленных проблем правового регулирования медиативных соглашений и соглашений о применении процедуры медиации посредством внесения изменений в действующее законодательство. Кроме того, автор обращает внимание на необходимость разработки практических рекомендаций по заключению медиативных соглашений в целях повышения их добровольного исполнения.

Ключевые слова: медиация, медиативное соглашение, договор, спор, конфликт, исполнение.

Цитирование. Степанова И. А. Соглашения, заключаемые в рамках процедуры медиации: вопросы эффективности // Legal Concept = Правовая парадигма. - 2018. - T. 17, № 4. - C. 117-124. - DOI: https://doi.org/ 10.15688/lc.jvolsu.2018.4.17

\section{Введение}

В настоящее время несудебные формы разрешения споров достаточно широко применяются в российской правовой системе. Внесудебные способы разрешения споров представляют собой многообразие комплексов мероприятий, методов, механизмов, которые направлены на разрешение конфликта вне судебной системы либо в качестве ее дополнительного элемента. Они возникли как альтернатива гражданскому судопроизводству, которое, несмотря на его значимость для об- щества в целом, является дорогостоящим, формальным, длительным и сложным для участников спора. Необходимость поиска иных методов - более простых, экономичных, быстрых и эффективных - привела к созданию «неформального правосудия» для разрешения правовых конфликтов. Возникнув как инструмент процессуальных преобразований, равно как метод преодоления кризисной ситуации в правосудии, альтернативные методы урегулирования конфликтов постепенно преобразуются в обязательную часть российской правовой системы. 
К числу альтернативных методов урегулирования конфликтов, постепенно набирающих популярность в бизнес-среде, относится медиация.

\section{Понятие медиации \\ как альтернативного метода урегулирования \\ гражданско-правовых конфликтов}

Действующий Федеральный закон от 27.07.2010 № 193-Ф3 «Об альтернативной процедуре урегулирования споров с участием посредника (процедуре медиации)» (далее - Закон о медиации) закрепляет определение понятия «процедура медиации», не раскрывая при этом термин «медиация». Согласно п. 2 ст. 2 названного закона процедура медиации - способ урегулирования споров при содействии медиатора на основе добровольного согласия сторон в целях достижения ими взаимоприемлемого решения [22].

Следует отметить, что Закон о медиации регулирует отношения, связанные с применением процедуры медиации к спорам, возникающим из гражданских правоотношений, в том числе в связи с осуществлением предпринимательской и иной экономической деятельности, а также спорам, возникающим из трудовых и семейных [2, с. 32] правоотношений (п. 2 ст. 1 названного закона) [10, c. 515]. В то же время намеренно оставленный законодателем открытым перечень способов защиты прав предоставил россиянам новые возможности для защиты своих прав $[15$, c. 21$]$.

Несмотря на то что в Законе о медиации имеется четкое определение понятия «процедура медиации», среди представителей как юридической, так и экономической науки, а также среди ученых-лингвистов и социологов ведутся дискуссии по вопросу об определении понятия «медиация».

По мнению известного российского медиатора Ц.А. Шамликашвили, члена Ассоциации интегрированной медиации, эксперта «International Mediation Institute» («IMI»), «медиация - это, прежде всего, особая технология разрешения конфликтов, к которой нужно подходить серьезно и обладать спе- циальными профессиональными медиативными навыками и умением определенного спокойствия» [23].

Кроме того, ведутся дискуссии по поводу использования категорий «способ» и «метод» при определении понятия «медиация».

В частности, А.А. Брыжинский определяет медиацию как «бесконфликтный» мирный способ рассмотрения любого спора и урегулирование его на «взаимной» основе [4, с. 111].

Т.А. Савельева полагает, что посредничество (медиация) - это способ урегулирования конфликта между сторонами на основе переговоров с участием нейтрального посредника с целью выработки обязательного для сторон соглашения по спорному вопросу $[9$, c. 34].

А.Ю. Коннов определяет медиацию как инструмент к получению «взаимовыгодных» условий с помощью заключения «мирного» соглашения [13, с. 123].

М.В. Гвоздарева указывает на такие признаки в определении посредничества (медиации), как «заглаживание» и «ликвидация» между спорящими сторонами причины «очага» конфликта [5, с. 16].

Сущность медиативной деятельности раскрывают и через ее главную цель - устранение любой тяжести конфликта путем переговоров, так как медиация - составной элемент примирительной процедуры [21, c. 185$]$.

Социологи и экономисты придерживаются единого мнения и определяют медиацию как деятельность, осуществляемую специалистами, наделенными умением контролировать и направлять спорящие стороны в нужное русло, медиатор - это не психолог и не юрист, а лицо, которое имеет базовое образование конфликтолога [11]. Такая примирительная процедура является главным инструментом для разрешения различной степени конфликтов с привлечением нейтральной третьей стороны $[8$, с. 8$]$.

Соответственно, в целях благоприятного экономического развития государства при разрешении конфликтов выгодно использовать институт медиации [3, с. 7], объективной формой выражения которого выступает соответствующее соглашение. 


\section{Сущность медиативного соглашения, заключенного без передачи спора на рассмотрение суда}

Вопросы об определении понятия «медиативное соглашение», «соглашение о применении процедуры медиации», его форме и обязательных условиях подробно регламентированы Законом о медиации.

Исходя из анализа указанного специального закона, возможно выделить следующие виды заключаемых сторонами соглашений:

- соглашение о применении процедуры медиации;

- соглашение о проведении процедуры медиации;

- медиативное соглашение.

Правовую природу медиативного соглашения, достигнутого сторонами до передачи спора на рассмотрение в суд, законодатель определил в п. 4 ст. 12 Закона о медиации. В частности, рассматриваемое медиативное соглашение представляет собой гражданскоправовую сделку, поэтому в случае его неисполнения или ненадлежащего исполнения защита нарушенных прав осуществляется способами, предусмотренными гражданским законодательством [17].

В литературе также преобладает подход о признании медиативного соглашения, заключенного до передачи спора на рассмотрение суда, гражданско-правовой сделкой [19, с. 28].

Действительно, подтверждение обоснованности указанной позиции вытекает как из ст. 153 ГК РФ, так и из доктрины гражданского права [6, с. 437].

Вместе с тем многие исследователи утверждают, что медиативное соглашение, заключенное сторонами до передачи спора на рассмотрение суда, не сводится к гражданско-правовой сделке [24], так как процедура медиации может использоваться для разрешения споров, возникающих из трудовых и семейных правоотношений.

Кроме того, в литературе возможно обнаружить неоднозначное отношение к перспективам использования медиативных соглашений для урегулирования конфликтов.

Так, по мнению М.Н. Кузьминой, медиация и иные альтернативные способы разрешения юридических конфликтов «вряд ли спо- собны быть эффективными в России». Связано это с тем, что в стране «судебное разбирательство имеет краткие сроки (2-3 месяца), экономически выгодно, так как размер госпошлины невысок и не повышается в зависимости от судебной инстанции, судебное решение оказывается более исполнимым, нежели взаимное соглашение». Единственным стимулом для развития медиации и заключения соответствующих соглашений в России является желание снизить нагрузку на судей $[14$, c. 222].

Данная позиция имеет право на существование, но в корне не соответствует действительности.

Во-первых, требуется девять месяцев, чтобы соблюсти все предусмотренные АПК РФ процессуальные сроки рассмотрения дела в арбитражном суде первой, апелляционной и кассационной инстанций.

Во-вторых, кроме оплаты госпошлины, стороны несут и иные судебные расходы. Напротив, в рамках заключения медиативного соглашения все эти расходы значительно снижаются, тем самым опровергая высказывание об экономической выгодности участия в судебном процессе [19, с. 54].

В-третьих, судебное решение нельзя назвать более исполнимым. Как справедливо отмечает Д. Давыденко, характерной для медиации является малая вероятность «несоблюдения достигнутого соглашения по сравнению с решением, вынесенным судьей или арбитром, поскольку стороны являются “соавторами" этого соглашения» [7, с. 108].

Таким образом, преимущества заключения медиативного соглашения до передачи спора на рассмотрение в суд обусловлены преимуществами самого альтернативного метода. В частности, медиативное соглашение в отличие от судебного решения носит конфиденциальный характер и не размещается в публичном доступе, стороны самостоятельно с учетом требований законодательства устанавливают сроки проведения процедуры, ее порядок, а также самостоятельно несут все расходы, возникающие в связи с урегулированием конфликта посредством медиации, которые в дальнейшем не компенсируются [16].

Несмотря на внешнюю простоту и удобство соглашений, предусмотренных Законом 
о медиации, на практике по результатам заключения возникает ряд проблем.

\section{Проблемы правового регулирования отдельных видов соглашений, связанных с процедурой медиации}

Обязательность использования медиации в качестве альтернативного метода урегулирования конфликта может быть предусмотрена сторонами заранее в заключаемом договоре (медиативная оговорка) или предложена одной из сторон впоследствии в целях разрешения возникшего конфликта без обращения в суд [12].

Вместе с тем в судебной практике возможно обнаружить позицию, основанную на п. 2 ст. 2, п. 3 ст. 7 Закона о медиации, согласно которой наличие в договоре медиативной оговорки не является препятствием для обращения в суд, так как медиация - это один из альтернативных способов урегулирования спора, а не обязательный досудебный порядок $[1 ; 18]$.

Следует отметить, что анализ п. 3 ст. 7 Закона о медиации позволяет утверждать, что возможность обратиться в суд, несмотря на наличие медиативной оговорки в договоре, имеется, если иное не предусмотрено федеральными законами. Однако до настоящего времени соответствующих федеральных законов принято не было.

Кроме того, п. 1 ст. 4 Закона о медиации прямо указывает, что если стороны в рамках заключенного соглашения о применении процедуры медиации приняли на себя обязательство не обращаться в суд за разрешением спора в течение конкретного периода, то суд признает силу этого обязательства до момента их исполнения. Вместе с тем, если одной из сторон необходимо, по ее мнению, защитить свои права, обращение в суд возможно и ранее оговоренного сторонами срока.

На наш взгляд, формулировка «по ее мнению» создает противоречивую ситуацию, при которой суд признает силу соглашения о применении процедуры медиации лишь до момента обращения к нему с просьбой о защите и, соответственно, после подачи иска суд беспрепятственно примет его к производству, а это в целом будет означать, что зак- люченное соглашение не имеет никакой юридической силы. Существование описанной практики прямо противоречит п. 1 ст. 4 Закона о медиации.

Другой проблемой, заслуживающей внимания в рамках настоящего исследования, является проблема исполнимости медиативных соглашений, достигнутых сторонами без обращения в суд и не утвержденных им в качестве мирового соглашения.

Как следует из п. 2 ст. 12 Закона о медиации, такое соглашение подлежит исполнению на основе принципов добровольности и добросовестности сторон.

Вместе с тем действующим законодательством не предусмотрены какие-либо механизмы его принудительного исполнения, что, на наш взгляд, в целом является фактором, негативно отражающимся на популяризации медиации как альтернативном методе урегулирования конфликтов.

\section{Выводы}

Полагаем, что в целях разрешения обозначенных в работе проблем правового регулирования, негативно отражающихся на эффективности соглашений, предусмотренных Законом о медиации, необходимо внести ряд изменений в действующее законодательство.

В целях устранения проблемы, связанной со значением соглашения о применении процедуры медиации, следует исключить формулировку «по ее мнению» из п. 1 ст. 4 Закона о медиации. Предлагаемая мера позволит придать соглашению о применении процедуры медиации до обращения в суд силу факта, имеющего обязательное значение для возбуждения дела судом.

Что же касается проблемы отсутствия механизма принудительного исполнения медиативного соглашения, то, на наш взгляд, возможно предложить два варианта ее устранения.

Первый вариант возможно считать достаточно кардинальным, его сущность выражается в следующем: по результатам применения медиации как одного из альтернативных методов урегулирования конфликта стороны (без передачи спора на рассмотрение суда) заключают медиативное соглашение, которое впоследствии передают в суд для его провер- 
ки и утверждения, а также получения исполнительного листа в случае, если имеет место факт неисполнения медиативного соглашения. В случае реализации описанного варианта на практике потребуется внести изменения в ст. 12 Закона о медиации, а также в соответствующие положения АПК РФ и ГПК РФ.

Второй вариант представляется достаточно компромиссным и заключается в установлении в законодательстве требования об обязательной нотариальной форме медиативного соглашения, заключенного сторонами без обращения в суд. При этом нотариально удостоверенное медиативное соглашение должно иметь силу исполнительного листа. Соответствующие изменения следует внести как в ст. 12 Закона о медиации, так и в Основы законодательства Российской Федерации о нотариате (утв. ВС РФ 11.02.1993 № 4462-1).

Кроме того, потребуется в целом пересмотреть роль нотариуса в рамках медиации как альтернативного метода урегулирования конфликтов.

Представляется, что вспомогательным механизмом, содействующим добровольному исполнению медиативных соглашений, достигнутых сторонами без обращения в суд, выступает разработка практических рекомендаций по их заключению.

\section{СПИСОК ЛИТЕРАТУРЫ}

1. Апелляционное определение Липецкого областного суда от 24.06.2015 по делу № 33-1491/ 2015. - Доступ из справ.-правовой системы «КонсультантПлюс».

2. Бахарева, О. А. Урегулирование семейных споров посредством процедуры медиации / О. А. Бахарева, О.В.Николайченко // Арбитражный и гражданский процесс. - 2017. - № 7. - С. 32-36.

3. Березинская, О. Инвестиционный процесс в российской экономике: потенциал и направленная активизация / О. Березинская, А. Ведев // Вопросы экономики. - 2014. - № 4. - С.4-16.

4. Брыжинский, А. А. Проблемы и перспективы развития медиации / А. А. Брыжинский, Т. В. Худойкина // Правовая политика и правовая жизнь. - 2011. - № 3. - С. 109-115.

5. Гвоздарева, М. В. Посредничество как метод альтернативного разрешения корпоративных конфликтов : автореф. дис. ... канд. социол. наук / Гвоздарева Марина Владимировна. - М., 2006. -23 с.
6. Гражданское право : учебник. В 3 т. Т. 1 / Е. Н. Абрамова, Н. Н. Аверченко, Ю. В. Байгушева [и др.]; под ред. А. П. Сергеева. - М. : ТК Велби, 2008. - 1008 с.

7. Давыденко, Д. Медиация как примирительная процедура в коммерческих спорах: сущность, принципы, применимость / Д. Давыденко // Хозяйство и право. - 2005. - № 5. - С. 105-111.

8. Дробышевский, С. Макроэкономические предпосылки реализации новой модели роста / С. М. Дробышевский, С. Г. Синельников-Мурылев // Вопросы экономики. - 2012. - № 9. - С. 4-24.

9. Зайцев, А. М. Негосударственные процедуры урегулирования правовых споров : учеб. пособие / А. М. Зайцев, Н. В. Кузнецов, Т. Л. Савельева. - Саратов, 2000. - 342 с.

10. Иванова, Л. В. К вопросу о понятии медиации в российском праве / Л. В. Иванова // Молодой ученый. - 2015. - № 13. - С. 514-516.

11. Интервью с социологом О.В. Мавриным // Федеральный образовательный портал. - Электpoн. текстовые дан. - Режим доступа: http:// ecsocman.hse.ru/text/35406631/ (дата обращения: 01.09.2018). - Загл. с экрана.

12. Иншакова, А. О. Альтернативные способы урегулирования корпоративных конфликтов / А. О. Иншакова // Новейшие юридические технологии: гражданский процесс, арбитражный процесс, альтернативные способы разрешения споров : материалы Круглого стола, г. Волгоград, 18 мая 2012 г. - Волгоград : Изд-во ВолГУ, 2012.C. $100-106$.

13. Коннов, А. Ю. Понятие, классификация и основные виды альтернативных способов разрешения споров / А. Ю. Коннов // Журнал российского права. - 2004. - № 12. - С. 120-131.

14. Кузьмина, М. Н. Юридический конфликт: теория и практика разрешения / М. Н. Кузьмина. М., 2008. -256 c.

15. Минкина, Н. И. Медиация как способ урегулирования конфликтов, возникающих из правоотношений в области здравоохранения / Н. И. Минкина // Медицинское право. - 2017. - № 6. - С. 21-25.

16. Постановление Пленума Верховного Суда РФ от 21.01.2016 № 1 «О некоторых вопросах применения законодательства о возмещении издержек, связанных с рассмотрением дела» // Бюллетень Верховного Суда РФ. - 2016. - № 4.

17. Разъяснения Минэкономразвития РФ от 27.05.2011 «Позиция Минэкономразвития России по вопросам, связанным с применением Федерального закона от 27 июля 2010 г. № 193-Ф3 “Об альтернативной процедуре урегулирования споров с участием посредника (процедуре медиации)"». - Доступ из справ.-правовой системы «КонсультантПлюс». 
18. Решение Арбитражного суда Ростовской области по делу № А53-769/2011 от 18 апреля 2011 года. - Доступ из справ.-правовой системы «КонсультантПлюс».

19. Ротко, С. В. Третейское и медиативное рассмотрение споров в системе альтернативного разрешения гражданско-правовых конфликтов / С. В. Ротко // Юрист. - 2014. - № 3. - С. 28-33.

20. Скворцов, О. Ю. Третейское соглашение: допустимо ли его распространение на выгодоприобретателя, не заключавшего его? / О. Ю. Скворцов // Третейский суд. - 2016. - № 6 (108). - С. 52-54.

21. Тихонова, Е. А. Некоторые вопросы интеграции примирительных процедур в гражданский и Арбитражный процесс / Е. А. Тихонова //Альманах современной науки и образования. 2013. - № 4 (71). - С. 185-189.

22. Федеральный закон «Об альтернативной процедуре урегулирования споров с участием посредника (процедуре медиации)» от 27.07.2010 № 193-Ф3// Собрание законодательства РФ. - 2010. 2 авг. (№ 31). - С. 4162.

23. Центр медиации и права // Правовой портал. - Электрон. текстовые дан. - Режим доступа: http://www.mediacia.com/publications/81.html (дата обращения: 01.09.2018). - Загл. с экрана.

24. Шеменева, О. Н. Роль соглашений сторон в гражданском судопроизводстве / О. Н. Шеменева. - М. : Инфотропик Медиа, 2017. - 312 с. Доступ из справ.-правовой системы «КонсультантПлюс».

\section{REFERENCES}

1. Apellyatsionnoe opredelenie Lipetskogo oblastnogo suda ot 24.06.2015 po delu № 33-1491/ 2015 [Appeal Resolution of the Lipetsk Regional Court of 24 June 2015 on Case No. 33-1491/2015]. Access from Reference Legal System 'KonsultantPlyus'.

2. Bakhareva O.A., Nikolaychenko O.V. Uregulirovanie semeynykh sporov posredstvom protsedury mediatsii [Settlement of Family Disputes by Means of Mediation Procedure]. Arbitrazhnyy $i$ grazhdanskiy protsess, 2017, no. 7, pp. 32-36.

3. Berezinskaya O., Vedev A. Investitsionnyy protsess $\mathrm{v}$ rossiyskoy ekonomike: potentsial i napravlennaya aktivizatsiya [Investment Process in the Russian Economy: Potential and the Directed Activization]. Voprosy ekonomiki, 2014, no. 4, pp. 4-16.

4. Bryzhinskiy A.A., Khudoykina T.V. Problemy i perspektivy razvitiya mediatsii [Problems and Prospects of Mediation Development]. Pravovaya politika i pravovaya zhizn, 2011, no. 3, pp. 109-115.

5. Gvozdareva M.V. Posrednichestvo kak metod alternativnogo razresheniya korporativnykh konfliktov: avtoref. dis. ... kand. sotsiol. nauk [Mediation as a Method of Alternative Resolution of Corporate Conflicts. Cand. social. sci. abs. diss.]. Moscow, 2006. $23 \mathrm{p}$.

6. Abramova E.N., Averchenko N.N., Baygusheva Yu.V., et al. Grazhdanskoe pravo: uchebnik. V 3 t. T. 1 [Civil Law: Textbook. In 3 vols. Vol. 1]. Moscow, TK Velbi Publ., 2008. 1008 p.

7. Davydenko D. Mediatsiya kak primiritelnaya protsedura v kommercheskikh sporakh: sushchnost, printsipy, primenimost [Mediation as the Conciliatory Procedure in Commercial Disputes: Essence, Principles, Applicability]. Khozyaystvo i pravo, 2005, no. 5, pp. 105-111.

8. Drobyshevskiy S., Sinelnikov-Murylev S.G. Makroekonomicheskie predposylki realizatsii novoy modeli rosta [Macroeconomic Prerequisites of Realization of a Growth New Model]. Voprosy ekonomiki, 2012, no. 9, pp. 4-24.

9. Zaytsev A.M., Kuznetsov N.V., Savelyeva T.L. Negosudarstvennye protsedury uregulirovaniya pravovykh sporov [Non-State Procedures for Legal Disputes Settlement]. Saratov, 2000. 342 p.

10. Ivanova L.V. K voprosu o ponyatii mediatsii $\mathrm{v}$ rossiyskom prave [On the Concept of Mediation in the Russian Law]. Molodoy uchenyy, 2015, no. 13, pp. 514-516.

11. Intervyu s sotsiologom O.V. Mavrinym [Interview with the Sociologist O.V. Mavrin]. Federalnyy obrazovatelnyy portal [Federal Educational Portal]. URL: http://ecsocman.hse.ru/text/ 35406631/ (accessed 15 May 2017).

12. Inshakova A.O. Alternativnye sposoby uregulirovaniya korporativnykh konfliktov [Alternative Ways to Resolve Corporate Conflicts]. Noveyshie yuridicheskie tekhnologii: grazhdanskiy protsess, arbitrazhnyy protsess, alternativnye sposoby razresheniya sporov: materialy Kruglogo stola, g. Volgograd, 18 maya 2012 g. [Newest Legal Technologies: Civil Procedure, Arbitration Process, Alternative Dispute Resolution Methods. Proceedings of the Round Table (Volgograd, May 18, 2012)]. Volgograd, Izd-vo VolGU, 2012, pp. 100-106.

13. Konnov A.Yu. Ponyatie, klassifikatsiya i osnovnye vidy alternativnykh sposobov razresheniya sporov [Concept, Classification and Main Types of Alternative Ways of Disputes Settlement]. Zhurnal rossiyskogo prava, 2004, no. 12, pp. 120-131.

14. Kuzmina M.N. Yuridicheskiy konflikt: teoriya i praktika razresheniya [Legal Conflict: Theory and Practice of Resolution]. Moscow, 2008. $256 \mathrm{p}$.

15. Minkina N.I. Mediatsiya kak sposob uregulirovaniya konfliktov, voznikayushchikh iz pravootnosheniy $\mathrm{v}$ oblasti zdravookhraneniya [Mediation as a Way of Settlement of the Conflicts 
Arising from Legal Relationship in the Field of Health Care]. Meditsinskoe pravo, 2017, no. 6, pp. 21-25.

16. Postanovlenie Plenuma Verkhovnogo Suda RF ot 21.01.2016 № 1 «O nekotorykh voprosakh primeneniya zakonodatelstva o vozmeshchenii izderzhek, svyazannykh s rassmotreniem dela» [Resolution of the Plenum of the Supreme Court of the Russian Federation of 21 January 2016 No. 1 'On Some Questions of Application of the Legislation on Compensation of the Costs Connected with Consideration of the Case']. Byulleten Verkhovnogo Suda RF, 2016, no. 4.

17. Razyasneniya Minekonomrazvitiya RF ot 27.05.2011 «Pozitsiya Minekonomrazvitiya Rossii po voprosam, svyazannym s primeneniem Federalnogo zakona ot 27 iyulya $2010 \mathrm{~g}$. № $193-\mathrm{FZ}$ «Ob alternativnoy protsedure uregulirovaniya sporov s uchastiem posrednika (protsedure mediatsii)» [Explanations of the Ministry of Economic Development of the Russian Federation of 27 May 2011 'Position of the Ministry of Economic Development of the Russian Federation on the Questions Connected with Application of the Federal Law of July 27, 2010 No. 193-FZ 'About the Alternative Procedure of Disputes Settlement with Participation of the Intermediary (the Procedure of Mediation)']. Access from Reference Legal System 'KonsultantPlyus'.

18. Reshenie Arbitrazhnogo suda Rostovskoy oblasti po delu № A53-769/2011 ot 18 aprelya 2011 goda [Decision of Arbitration Court of the Rostov Region on Case No. A53-769/2011 of April 18, 2011]. Access from Reference Legal System 'KonsultantPlyus'.

19. Rotko S.V. Treteyskoe i mediativnoe rassmotrenie sporov $\mathrm{v}$ sisteme alternativnogo razresheniya grazhdansko-pravovykh konfliktov [Arbitration and Mediation Consideration of Disputes in the System of Alternative Permission of the Civil Conflicts]. Yurist, 2014, no. 3, pp. 28-33.

20. Skvortsov O.Yu. Treteyskoe soglashenie: dopustimo li ego rasprostranenie na vygodopriobretatelya, ne zaklyuchavshego ego? [Arbitration Agreement: Is It Acceptable to Distribute It to a Beneficiary Who Does not Enter into It?]. Treteyskiy sud, 2016, no. 6(108), pp. 52-54.

21. Tikhonova E.A. Nekotorye voprosy integratsii primiritelnykh protsedur v grazhdanskiy i Arbitrazhnyy protsess [Some Issues of Conciliation Procedures Integration in the Civil and Arbitration Process]. Almanakh sovremennoy nauki $i$ obrazovaniya, 2013, no. 4 (71), pp. 185-189.

22. Federalnyy zakon «Ob alternativnoy protsedure uregulirovaniya sporov s uchastiem posrednika (protsedure mediatsii)» ot 27.07.2010 № 193-FZ [Federal Law 'On the Alternative Procedure for the Settlement of Disputes with the Participation of the Mediator (the Mediation Procedure)» No. 193-FZ of July 27, 2010]. Sobranie zakonodatelstva RF [Collected Legislation of the Russian Federation], 2010, no. 31 , art. 4162 .

23. Tsentr mediatsii i prava [Center of Mediation and Law]. Pravovoy portal [Legal Portal]. URL: http:/ /www.mediacia.com/publications/81.html (accessed 15 May2018).

24. Shemeneva O.N. Rol soglasheniy storon v grazhdanskom sudoproizvodstve [The Role of Agreements of the Parties in Civil Legal Proceedings]. Moscow, Infotropik Media, 2017. 312 p. Access from Reference Legal System 'KonsultantPlyus'.

\section{Information about the Author}

Irina A. Stepanova, Notary of Volgograd, Marshala Eremenko St., 19, 400123 Volgograd, Russian Federation, sia-may@yandex.ru, https://orcid.org/0000-0003-2296-9368

\section{Информация об авторе}

Ирина Александровна Степанова, нотариус г. Волгограда, ул. им. маршала Еременко, 19, 400123 г. Волгоград, Российская Федерация, sia-may@yandex.ru, https://orcid.org/0000-00032296-9368 